\title{
GEREJA SEBAGAI PERSEKUTUAN PERSAHABATAN YANG TERBUKA MENURUT JÜRGEN MOLTMANN
}

\author{
Yohanes Krismantyo Susanta \\ Institut Agama Kristen Negeri Toraja \\ yohanessusanta@gmail.com
}

\begin{abstract}
By using a qualitative descriptive approach, this article shows that according to Moltmann, the concept of the church as fellowship or Koinonia is too often based on uniformity. Against the Koinonia model, Moltmann raised the biblical concept of the importance of strangers and travelers, outcasts, and sinners. According to Moltmann, the church cannot be a boat of sameness in navigating the ocean of diversity. Therefore, Moltmann offers the concept of a trinitarian partnership based on friendship. For Moltmann, the good news about Koinonia from the Triune God is not marked by friendship in uniformity, but by a friendship that unites, respects, and embraces differences. True Koinonia means more than just accepting and embracing tension and conflict. True Koinonia is about accepting and embracing each other (and also God). The ultimate sign of true Koinonia is friendship. Moltmann emphasized the church's call to be an open fellowship of friendship by promoting freedom, equality, and love. Moltmann, at the same time, put forward a criticism of the church structure which - in Moltmann's terms - was built on the principle of monotheistic hierarchy, which was actually loaded with oppression.
\end{abstract}

Keywords: koinonia, friendship, church, trinity, Jürgen Moltmann

\begin{abstract}
Abstrak. Dengan menggunakan pendekatan kualitatif deskriptif, artikel ini memperlihatkan bahwa menurut Moltmann, konsep gereja sebagai persekutuan atau koinonia terlalu sering didasarkan pada keseragaman. Terhadap model koinonia tersebut, Moltmann mengangkat konsep Alkitabiah tentang arti penting dari orang asing dan musafir, orang buangan dan pendosa. Menurut Moltmann, gereja tidak bisa menjadi sebuah perahu kesamaan (a boat of sameness) dalam mengarungi lautan keberbedaan. Oleh karena itu, Moltmann menawarkan konsep persekutuan trinitaris yang berdasar pada persahabatan. Bagi Moltmann, kabar baik tentang koinonia dari Allah Tritunggal tidak ditandai oleh persahabatan keseragaman, tetapi oleh persahabatan yang menyatukan, menghormati dan mencakup perbedaan. Koinonia sejati berarti lebih dari sekadar menerima dan merangkul ketegangan dan konflik. Koinonia sejati adalah tentang menerima dan memeluk satu sama lain (dan juga Allah). Tanda pamungkas dari koinonia sejati adalah persahabatan. Moltmann menekankan panggilan gereja untuk menjadi persekutuan persahabatan (friendship koinonia) yang terbuka dengan mengedepankan kebebasan, kesetaraan dan cinta kasih. Moltmann sekaligus mengajukan kritik terhadap struktur gereja yang - dalam istilah Moltmann - dibangun dengan prinsip hierarkhi monoteis yang justru sarat dengan penindasan.
\end{abstract}

Kata Kunci: koinonia, persahabatan, gereja, tritunggal, Jürgen Moltmann

Sebuah ide popular dan dikenal luas mengatakan bahwa manusia adalah makhluk sosial yaitu makhluk yang senantiasa membutuhkan kehadiran orang lain. Manusia tidak bisa hidup tanpa orang lain. Sementara Jozef Pieniazek mengatakan "manusia menjadi manusia 
melalui manusia yang lain.” (Dalam Baghi, 2012, hal. vi). Hal ini tentu bukanlah sesuatu yang baru, akan tetapi isu tentang orang lain atau sang liyan masih menjadi diskursus yang menarik dalam studi ilmu sosial dan teologi. Hal ini paling tidak dibuktikan lewat sejumlah tulisan yang mengangkat isu tentang yang lain (the other). Bahkan isu tersebut juga menjadi concern para filsuf besar mulai dari Derrida, Levinas, hingga Julia Kristeva. (Derrida, 2005; Kristeva, 1991; Levinas, 2000).

Dalam terang filsafat, yang bukan "aku" kerap dilihat sebagai persoalan. Subyek yang egoistis selalu melihat yang lain sebagai yang bukan aku. Menurut Jean Paul Satre, afirmasi terhadap diri sebagai subyek hanya mungkin lewat jalan negasi terhadap yang lain. "Di luar aku, tidak ada yang eksis." Penyangkalan total ini tentu lahir dari kesadaran diri bahwa eksistensi yang lain adalah eksistensi yang asing, bukan bagian dari duniaku. (dalam Baghi, 2012, hal. 25).

Dalam tulisannya, Septemmy Lakawa menyebut "yang lain" bukan saja berarti "yang berbeda" melainkan juga bisa bermakna "yang diobyektifikasi”. (Lakawa, 2002, hal. 13). Sementara menurut Joas Adiprasetya, secara umum, kehadiran sang lain kerap dianggap sebagai kerikil tajam dalam relasi.

Kita harus hidup bersama dengan identitas bersama (common identity), dasar bersama (common ground) dan demi kebaikan bersama (common good). Singkatnya, berdasarkan the sameness. Harus ada sebuah elemen objektif yang menjadi pemersatu seluruh entitas yang ada. Maka, ketidaksesuaian Sang Lain dengan elemen objektif tersebut menempatkan dirinya sebagai aktor antagonis yang subversive. (Adiprasetya, 2002, hal. 45). 
Artikel ini berupaya menyorot "yang lain" sebagai entitas yang tidak terpisahkan dari hidup seorang atau komunitas masyarakat, termasuk gereja dalam konteks persekutuan dengan "yang lain." Ide tentang persekutuan atau koinonia akan mengingatkan pembaca kepada pemahaman klasik mengenai tri tugas panggilan gereja yaitu kesaksian (marturia), persekutuan (koinonia), dan pelayanan (diakonia). Persekutuan atau koinonia merupakan salah satu bukti bahwa umat manusia membutuhkan perjumpaan dengan yang lain. Martha Nussbaum mengatakan,

hidupmu tidak hanya berurusan dengan dirimu sendiri. Hidup itu soal bagaimana menerima kenyataan bahwa engkau rela berbagi bersama yang lain, dan bagaimana engkau melakukan perbuatan baik bagi yang lain... Kenalilah dirimu sendiri, agar engkau dapat bergerak ke luar dirimu untuk melakukan keadilan dan memperjuangkan perdamaian. (dalam Baghi, 2012, hal. vii).

Akan tetapi, seorang teolog Jerman, Jürgen Moltmann mengajukan kritik terhadap gereja terkait dengan sikap terhadap yang lain. Dalam bukunya yang terkenal, Trinity and the Kingdom, Moltmann menyebut bahwa gereja gagal menjadi komunitas para sahabat tetapi sebaliknya menjadi struktur yang menindas karena mengakomodir politik monoteis dan monoteisme klerus (clerical monotheism). (Moltmann, 1993). Gereja juga kerap kali gagal membangun koinonia yang sejati karena sempitnya pemahaman akan koinonia tersebut. Di sinilah pentingnya konsep eklesiologi Moltmann diteliti lebih jauh guna melihat sumbangsihnya bagi kehidupan bergereja. Artikel ini bertujuan menelusuri jejak pemikiran Moltmann dalam kaitannya dengan topik gereja sebagai persekutuan 
persahabatan yang terbuka, termasuk kepada yang lain. Dalam Bukunya, Theology of Hope, Moltmann menyebut pentingnya gereja memperlakukan yang lain: "gereja tidak hadir untuk dirinya sendiri, melainkan ia ada untuk orang lain. Ini adalah Gereja Allah di mana ia adalah gereja yang hadir untuk dunia." (Moltmann, 1975, hal. 327).

\section{METODE}

Penelitian ini menggunakan metode kualitatif dengan pendekatan studi pustaka. Literatur yang digunakan adalah buku-buku dan jurnal terkait dengan konsep Jürgen Moltmann tentang gereja, tritunggal, persekutuan dan persahabatan. Literatur primer dari tulisan ini adalah buku karya Moltmann, secara khusus tiga buku yang menyinggung persoalan ini yaitu Trinity and the Kingdom, The Church in the Power of the Spitit, dan Theology of Hope. Sumber sekunder berupa jurnal yang membahas pemikiran Moltmann.

Adapun metode penelitian ini termasuk dalam ranah penelitian sosial deskriptif dengan menggunakan analisis interaktif (Adimihardja, 2011) di mana setelah mengumpulkan sejumlah literatur terkait topik ini, penulis akan melakukan reduksi data untuk memilih data yang relevan kemudian melakukan interpretasi data. Proses analisis interaktif akan menghasilkan konsep pemahaman akan gereja persahabatan yang terbuka kepada sang liyan berdasarkan teori yang diusung oleh Moltmann. 


\section{HASIL}

\section{Koinonia sebagai Persekutuan Persahabatan dengan Yang Lain: Kritik dan Tawaran Jürgen Moltmann}

Dalam buku berjudul Trinity and the Kingdom, Moltmann mengajukan tesis bahwa monoteisme dapat mengarah ke monarkisme. Oleh sebab itu, Moltmann menyebut bahwa gereja dapat memakai perspektif Trinitarian dari doktrin Trinitas guna mengatasi politik monoteisme karena monoteisme agama dapat berkembang menjadi monoteisme politik dan, lebih lanjut, menjadi absolutisme. (Moltmann, 1993).

Politik yang bermotif agama monoteisme selalu digunakan untuk melegitimasi dominasi, mulai dari kultus kaisar (emperor cults) pada dunia kuno, Bizantium dan ideologi absolut dari abad ketujuh belas, hingga kediktatoran pada abad kedua puluh. Sebaliknya, berlawanan dengan itu, doktrin Trinitas dikembangkan sebagai doktrin teologis tentang kebebasan dan kesetaraan. (Moltmann, 1993). Inilah yang menjadi alasan awal mengapa Moltmann menyebut bahwa kendati mengusung konsep koinonia, akan tetapi praktik koinonia yang berlangsung disusupi dengan pemikiran dan relasi dominasi-subordinasi. Hal tersebut bukanlah gambaran koinonia yang ideal dan sejati. Itu sebabnya konsep koinonia yang dipraktikkan oleh gereja perlu untuk direkonstruksi ulang.

Selanjutnya, menurut Moltmann, bentuk monoteisme monarkis lainnya di tubuh gereja juga dapat ditemukan dalam doktrin dan praktik monarki keuskupan dan pengembangan lebih lanjut dalam ajaran tentang 
kedaulatan Paus. (Moltmann, 1993). Monoteisme klerus berasal dari prinsip yang dirumuskan oleh Ignatius dari Antiokhia, yaitu, satu Tuhan satu Kristus - satu uskup - satu gereja, dan prinsip ini telah dikembangkan menjadi doktrin otoritas pemimpin gereja, yang masih ada sampai hari ini. Peristiwa Yesus dan Petrus di Kaisarea Filipi (Matius 16.13-20) tidak memberikan dukungan teologis yang cukup untuk peran Paus. Sebaliknya, pembenaran untuk kesatuan gereja harus didasarkan pada Yohanes 17.20 ("Supaya mereka semua menjadi satu; sama seperti Engkau, Bapa, ada di dalam Aku dan Aku di dalam kamu ... "). Persatuan yang digambarkan di sini adalah 'trinitarian', bukan hierarkis. Gereja trinitarian adalah komunitas yang bebas dari kekuasaan (dominasi). Sebaliknya, ia adalah komunitas kerukunan dan harmoni (Moltmann, 1993). Menurut Karkkainen, tesis yang diajukan Moltmann sederhana dan berani: masyarakat manusia, termasuk gereja, harus mencerminkan prinsip egalitarianisme yang terdapat dalam doktrin Tritunggal. (Karkkainen, 2005).

Moltmann mengkritik konsep koinonia yang selama ini dianut oleh gereja. Konsep gereja sebagai persekutuan atau koinonia terlalu sering didasarkan pada keseragaman. Hal inilah yang menjadi dasar kritik Moltmann bahwa gereja cenderung eksklusif dan menutup diri terhadap perbedaan. Menurut Moltmann, gereja tidak bisa menjadi sebuah perahu kesamaan (a boat of sameness) dalam mengarungi lautan keberbedaan. Oleh karena itu, Moltmann menawarkan konsep persekutuan trinitaris 
yang berdasar pada persahabatan. Bagi Moltmann, kabar baik tentang koinonia dari Allah Tritunggal tidak ditandai oleh persahabatan keseragaman, tetapi oleh persahabatan yang menyatukan, menghormati dan mencakup perbedaan. (dalam Rhodes, 2000). Harapan ini tercermin lewat gereja yang seharusnya menjadi persekutuan persahabatan yang terbuka bagi orang lain. (Rhodes, 2000). Harald Hegstad bahkan menyebut bahwa Moltmann percaya bahwa konsep persahabatan adalah sentral atau pusat dari konsep eklesiologi. (Hegstad, 2013).

Dalam penelitiannya, Nindyo Sasongko mengungkapkan bahwa memang istilah koinonia memiliki kekayaan makna sebagaimana yang diformulasikan oleh The Faith and Order Commission dalam konferensi yang diselenggarakan pada tahun 1993 di Santiago de Compostela, Spanyol. Kata koinonia dapat diterjemahkan dengan persekutuan (fellowship), berbagi (sharing), komunitas (community), atau solidaritas (solidarity). Atribut-atribut tersebut dapat ditemukan fondasinya dalam diri Allah Tritunggal. (Sasongko, 2015).

Hal senada dengan itu juga diungkapkan oleh Karkkainen yang banyak mengutip Moltmann. Menurutnya natur gereja yang bercorak Trinitaris memiliki beberapa karakteristik yaitu relasionalitas, kehadiranuntuk-yang lain, non-dominasi, persatuan, dan perbedaan. (Karkkainen, 2017). 


\section{Relasionalitas}

Relasionalitas didasarkan pada persekutuan antara Bapa, Anak, dan Roh dalam hubungan timbal balik satu sama lain, yang secara tradisional dinamakan perichoresis mutual interpenetration. Tidak pernah menjadi lingkaran "tertutup", relasionalitas ilahi meliputi dan mengundang gereja dan kemanusiaan untuk berpartisipasi. Moltmann memaparkan implikasi eklesiologis yang lebih luas dan kompleks dari relasionalitas Allah Tritunggal:

Melalui pengutusan Roh yang kreatif, sejarah trinitarian menjadi sejarah yang terbuka bagi dunia, terbuka bagi pria dan wanita, dan terbuka untuk masa depan. Melalui pengalaman Roh pemberi kehidupan dalam iman, dalam baptisan, dan dalam persekutuan orang percaya, orang-orang diintegrasikan ke dalam sejarah Tritunggal. Melalui Roh Kristus mereka tidak hanya menjadi peserta dalam sejarah eskatologis ciptaan baru, tetapi melalui Roh Anak mereka juga menjadi peserta pada saat yang sama dalam sejarah trinitarian Allah sendiri. (dalam Karkkainen, 2017, hal. 286)

Konsep relasi ini menjadi penting, sebab sebagaimana diungkap oleh Linna Gunawan bahwa kerap kali terjadi keterpisahan antara dogma gereja (dalam konteks ini dogma Allah Tritunggal) dengan kehidupan nyata. Padahal, dogma tersebut adalah bagian dari hidup beriman seharihari. (Gunawan, 2019).

\section{Kehadiran untuk Yang-Lain.}

Sifat relasional Trinitas berarti bahwa setiap Pribadi Tritunggal hadir bersama dan untuk yang lain. Hadir dengan yang lain berarti mengambil posisi yang mengundang yang mendengar dan menerima yang lain, serta melibatkan gerakan ke arah yang lain. Istilah ek-stasis, secara harfiah 
"berdiri di luar diri sendiri," digunakan untuk menjelaskan kemungkinan berhubungan dengan yang lain dengan cara yang satu tidak terjebak dalam batas-batas diri sendiri. Implikasinya yang penting dijelaskan secara ringkas oleh Miroslav Volf: "Gerakan ini [menuju persekutuan] sendiri membuktikan kebebasan orang. Orang itu bebas karena melampaui batas-batas diri dan karena itu tidak ditentukan secara kausal oleh realitas alam atau sejarah yang diberikan". (dalam Karkkainen, 2017, hal. 287).

\section{Nondominasi}

Persekutuan Allah Tritunggal bebas dari segala bentuk dominasi dan hierarki yang menindas. Muthiah menjelaskan dengan baik:

Hubungan trinitarian dicirikan oleh nondominasi. Hubungannya bersifat konsensual (suka sama suka) dan bebas. Tidak seorang pun dalam Tritunggal yang menentukan apa yang harus dilakukan oleh pribadi yang lain. Tidak satu pribadi pun dari Trinitas memaksa yang lain untuk berpartisipasi dalam hubungan atau bertindak dengan cara tertentu. (dalam Karkkainen, 2017, hal. 287)

Terlalu sering, bentuk-bentuk struktur gereja hierarkis, yang sering menggemakan hierarki institusi pemerintahan sekuler, telah menyebabkan dominasi, bahkan pelecehan. Misalnya diskriminasi terhadap perempuan, menutup akses pelayanan dan tak memberikan posisi kepemimpinan kepada mereka. (Karkkainen, 2017).

\section{Kesatuan}

Teologi trinitarian kontemporer - mengikuti jejak Kapadokia dan bapak-bapak gereja Timur lainnya - dengan demikian tidak mengabaikan 
sentralitas persatuan dalam Trinitas. Memang, kepercayaan Kristen pada Allah Tritunggal adalah keyakinan pada satu Tuhan; bahkan doktrin trinitariannya adalah "monoteisme konkret." Namun persatuan itu bersifat relasional, karena itu adalah persatuan Bapa, Anak, dan Roh (perichoresis). (Karkkainen, 2017).

\section{Perbedaan/Keragaman}

Menurut Moltmann, alasan sederhana mengapa kesatuan saja tidak pernah dapat ditegaskan, berdasarkan baik pada Trinitas atau logika akal sehat adalah "Persatuan mengandaikan diferensiasi; jika tidak ada perbedaan, kita tidak memiliki apa pun untuk dipersatukan". (Moltmann, 1993, 171). Berkenaan dengan Tritunggal, aksioma dasar yang disepakati adalah bahwa "masing-masing pribadi memiliki sifat ilahi dengan cara yang tidak dapat dipertukarkan; masing-masing menyajikannya dengan caranya sendiri". (Moltmann, 1993, 171). Ini adalah salah satu pokok yang dikemukakan Agustinus dalam doktrin trinitasnya, yaitu bahwa Bapa bukanlah Putra dan Putra bukanlah Bapa, dan hal yang sama berlaku untuk Roh Kudus. Ungkapan "persatuan dalam keanekaragaman" dan "keragaman dalam persatuan" yang saat ini sering digunakan menggambarkan dengan baik hal tersebut. Gereja Kristen zaman dahulu melihat persatuan-dalam-keragaman/keragaman-dalam-persatuan diilustrasikan dengan sangat indah dalam banyak bahasa pada hari Pentakosta (Kisah Para Rasul 2). "Keragaman yang menandai umat Allah pada hari Pentakosta sangat kontras dengan kekuatan-kekuatan yang 
dihomogenisasi yang bekerja di Babel (Kej. 11) dan lebih menyukai keanekaragaman yang dapat ditemukan di kerajaan Allah eskatologis (Why 7: 9; 14: 6)". (Karkkainen, 2017, 288).

Kelima karakteristik yang seharusnya menjadi ciri gereja selaku persekutuan (koinonia) yang sejati juga ditandaskan oleh Miroslav Volf dalam bukunya, After Our Likeness: The Church as the Image of the Trinity. Bagi Volf, Gereja adalah persekutuan umat Allah yang terbuka (open church), persekutuan yang setara (equal community), serta persekutuan cinta-kasih (community of love). Hirarki dan relasi dominasisubordinasi bukanlah ciri khas gereja yang bersifat Trinitarian. (Volf, 1998). Berdasarkan hal ini semakin jelas bahwa konsep koinonia yang seharusnya diusung oleh gereja adalah koinonia persahabatan, sebuah persekutuan yang setara dan diwarnai oleh cinta kasih.

\section{PEMBAHASAN}

\section{Persekutuan Persahabatan yang Terbuka: Membuka dan Memberi Ruang Bagi Perbedaan}

Moltmann menyebut bahwa karakteristik utama dari sebuah gereja yang setia kepada Kristus adalah "persahabatan yang terbuka." Dengan ini, Moltmann menyebutkan bahwa gereja harus menjadi komunitas di mana "perlindungan publik dan penghargaan publik" diberikan kepada orang miskin, kepada pemungut pajak dan orang berdosa."Mereka yang sering ditolak oleh masyarakat, bukan untuk menjadi objek pelayanan Kristen (diobyektifikasi) tetapi harus dipahami sebagai subjek dalam 
kerajaan Allah, dan mereka yang adalah sesama anggota dengan Kristus di kerajaan tersebut". (dalam Rhodes, 2000, hal. 65-66). Senada dengan Moltmann, Zizioulas dengan tegas mengatakan:

tidak ada model lain untuk hubungan yang layak antara persekutuan dalam keberbedaan selain Allah trinitarian. Jika gereja ingin setia menjalankan tugas dan peran dalam dunia, ia harus mencoba untuk mencerminkan persekutuan dan keberbedaan yang ada di dalam Allah Tritunggal ... [di mana] keberbedaan merupakan kesatuan dari persatuan .... Kesatuan dalam diri Allah Tritunggal diekspresikan melalui koinonia (komunitas) yang tidak bisa dipecahkan, yang ada di antara ketiga pribadi, yang berarti bahwa keberbedaan bukanlah ancaman terhadap persatuan, tetapi sine qua non (harus ada dalam sebuah) persatuan". (dalam Rhodes, 2000, hal. 66).

Menurut Joas Adiprasetya, orang asing bukan hanya dianggap berbeda, tetapi kerap dianggap sebagai musuh atau monster daripada tamu atau sahabat. Ketakutan terhadap yang lain atau orang asing tersebut telah menjadi rasa takut yang dimiliki oleh gereja. (Adiprasetya, 2018). Oleh karena itu, ia mengusulkan konsep eklesiologi yang terbuka.

Menurutnya, agar eklesiologi terbuka menghasilkan visi yang masuk akal tentang gereja sebagai tanda dan antisipasi kerajaan Allah, tiga kriteria yang sama pentingnya harus dipenuhi. Pertama, konsep eklesiologis harus berakar dalam tradisi Kristen yang berpusat pada Allah Tritunggal. Kedua, harus akrab dengan orang-orang dalam konteks budaya mereka sendiri. Ketiga, hal itu harus mengganggu orang-orang Kristen dari secara pasif menikmati komunitas mereka sendiri, sehingga mereka akan bekerja demi cinta, keadilan, dan rekonsiliasi di luar tembok gereja. Dengan kata lain, ide gerejawi harus tradisional, kontekstual, dan 
misional. (Adiprasetya, 2018). Gagasan eklesiologi terbuka melihat gereja sebagai salah satu di antara banyak tanda kerajaan Allah di seluruh dunia. Secara umum diketahui bahwa gereja-gereja di Indonesia, terutama yang berada dalam konteks perkotaan dan yang tinggal di daerah yang tidak toleran terhadap agama lain, cenderung mempertahankan komunitas mereka dengan meminimalkan interaksi sosial mereka dengan nonKristen. Ironisnya, hal itu terjadi ketika mereka mengklaim diri sebagai saluran berkat bagi dunia sementara pada saat yang sama mengasingkan diri dari ruang publik yang lebih luas. (Adiprasetya, 2018).

Ide yang diusung Joas Adiprasetya tersebut jauh sebelumnya telah digemakan oleh Moltmann. Menurutnya, karakteristik utama dari sebuah gereja yang setia kepada Kristus adalah "persahabatan yang terbuka." Dengan ini, Moltmann menyebutkan bahwa gereja harus menjadi komunitas di mana "perlindungan publik dan penghargaan publik" diberikan kepada orang miskin, kepada pemungut pajak dan orang berdosa. "Mereka yang sering ditolak oleh masyarakat, bukan untuk menjadi objek pelayanan Kristen (diobyektifikasi) tetapi harus dipahami sebagai subjek dalam kerajaan Allah, dan mereka yang adalah sesama anggota dengan Kristus di kerajaan tersebut." (dalam Rhodes, 2000, hal. 65-66). Senada dengan Moltmann, Zizioulas dengan tegas mengatakan:

tidak ada model lain untuk hubungan yang layak antara persekutuan dalam keberbedaan selain Allah trinitarian. Jika Gereja ingin setia menjalankan tugas dan peran dalam dunia, ia harus mencoba untuk mencerminkan persekutuan dan keberbedaan yang ada di dalam Allah Tritunggal ... [di mana] keberbedaan merupakan kesatuan dari persatuan .... Kesatuan dalam diri Allah Tritunggal 
diekspresikan melalui koinonia (komunitas) yang tidak bisa dipecahkan, yang ada di antara ketiga pribadi, yang berarti bahwa keberbedaan bukanlah ancaman terhadap persatuan, tetapi sine qua non (harus ada dalam sebuah) persatuan. (dalam Rhodes, 2000, hal. 66).

Perbedaan adalah sebuah keniscayaan, termasuk dalam persekutuan (koinonia). Sebagaimana diungkap oleh Tinambunan bahwa terdapat 7 respons terhadap perbedaan yaitu: 1) Merayakan; 2) Memanfaatkan; 3) Menghargai; 4) Menerima; 5) Menolerir; 6) Menghindari, atau 7) Menyerang. (Tinambunan \& Toruan, 2010).

Terkait dengan itu, sebuah persekutuan tentu mencakup lima hal pertama di atas dan secara khusus merangkul sekaligus merayakan perbedaan. Moltmann menyebut bahwa gereja harus membuka diri bagi mereka yang berbeda, khususnya mereka yang menderita. Mengapa? Karena "inilah yang telah dilakukan Allah dalam salib Yesus Kristus." Melalui peristiwa penyaliban, Yesus mengungkapkan identitasnya di antara mereka yang telah kehilangan identitas mereka, di antara para penderita kusta, sakit, ditolak dan dihina, dan diakui sebagai Anak Manusia di antara mereka yang telah kehilangan hak kemanusiaannya. (Slade, 2009).

Yesus sering disebut sebagai "sahabat orang berdosa." Bagi Moltmann, kata "sahabat" di sini harus ditambahkan pada ketiga gelar Yesus yang diberikan oleh gereja yaitu nabi, imam dan raja. Hanya dengan cara inilah Yesus sungguh-sungguh dihadirkan sebagai sahabat dalam persekutuan orang-orang kudus (the communion of the saints), 
suatu persekutuan persahabatan yang benar-benar terbuka. (Slade, 2009). Jadi saat Yohanes berkata, "Kemudian Anak Manusia datang, la makan dan minum, dan kamu berkata: Lihatlah, la seorang pelahap dan peminum, sahabat pemungut cukai dan orang berdosa" (Luk. 7:34), Moltmann melihat model persahabatan ini sebagai keterbukaan yang radikal terhadap yang lain di dalam suatu komunitas masyarakat Yahudi yang tertutup pada zaman itu.

Selanjutnya dalam Yohanes 15:15 Yesus berkata bahwa ia tak lagi menyebut para murid sebagai hamba melainkan sahabat. Ini bukanlah sebutan yang mudah. Bagian ini tak bisa dilepaskan dari ayat sebelumnya yang mengatakan, "Tidak ada kasih yang lebih besar dari pada kasih seorang yang memberikan nyawanya untuk sahabat-sahabatnya" (Yoh. 15:13). Moltmann mengatakan melalui kematian Kristus dalam persahabatan, para murid menjadi sahabat-Nya untuk selamanya, dan mereka semua diundang untuk berpartisipasi dalam perjamuan mesianik, di mana mereka juga harus dikenal sebagai sahabat pemungut cukai dan orang berdosa. Inilah bentuk luapan sukacita Ilahi, "agar sukacitaku ada di dalam kamu" (Yoh. 15:11). Moltmann menyebut persahabatan yang Yesus ajarkan ini, yang penuh dengan pengharapan, sukacita, dan berisiko ini sebagai persahabatan yang terbuka. (Slade, 2009).

Hal ini sejalan dengan apa yang dikatakan oleh Knitter dalam bukunya Satu Bumi banyak Agama bahwa,

Penilaian terhadap perbedaan yang mengarah pada perjumpaan yang langgeng dan pengetahuan tentang yang lain menghasilkan 
suatu praksis perlawanan terhadap apa saja yang membuat orang lain tak berdaya. Jadi praksis pembebasan bukan hanya suatu praktik "yang baik" berhadapan dengan kejahatan yang tidak bisa ditoleransi, tetapi juga persyaratan yang diperlukan untuk mengakui sesuatu sebagai "benar" tentang perbedaan kultural orang lain. Bagaimana saya bisa menghormati dan mengakui keberlainan (otherness) seseorang kalau orang itu tidak diperbolehkan untuk menjadi apa yang ia inginkan? Jadi, persayaratan lain untuk memungkinkan adanya wacana sejati dengan orang lain yang identitasnya didominasi oleh struktur sosio-ekonomi atau rasa tau jender yang menindas adalah pertama-tama menentang secara aktif dan bertindak mengatasi dominasi itu. Jadi, merayakan perbedaan dan menentang dominasi menjadi dua elemen integral dalam satu tindakan wacana (Knitter, 2008, 129).

Moltmann menyampaikan sesuatu yang sangat spesifik dengan

persahabatan ketika dia mengklaim,

konsep persahabatan adalah cara terbaik untuk mengekspresikan hubungan yang membebaskan dengan Allah, persekutuan antara pria dan wanita dalam semangat kebebasan. Persahabatan muncul dari kebebasan, ada dalam kebebasan yang saling menguntungkan, dan menjaga kebebasan itu. Sahabat adalah orang yang mencintai dalam kebebasan. (dalam Slade, 2009, hal. 20)

Ketika persahabatan terbuka yang Yesus tawarkan menjadi praktik dan kesaksian sebuah gereja, maka gereja itu berpotensi akan berselisih dengan masyarakat yang tertutup. Peter Slade yang mengutip Moltmann mengurai dengan sangat apik hal ini dengan menegaskan bahwa Gereja Kristen tidak harus melayani umat manusia yang tetap berharap agar dunia ini tetap seperti apa adanya, atau dilestarikan dalam keadaan di mana ia berada. Sebaliknya, gereja melayani masyarakat agar dapat mengubah dirinya sendiri. Misi gereja tidak dilakukan dalam cakrawala harapan yang diberikan oleh peran sosial yang diberikan masyarakat kepada Gereja, tetapi itu terjadi dalam cakrawala khasnya sendiri dari 
harapan eskatologis akan kedatangan Kerajaan Allah. Dengan kata lain, Gereja justru harus khawatir ketika menemukan dirinya cocok dengan masyarakat yang lebih besar. Sebaliknya, Gereja harus selalu menemukan dirinya digosokkan dengan kasar terhadap kawat berduri yang membatasi masyarakat karena melihat kerajaan yang akan datang berada di sisi lain pagar. (Slade, 2009).

Persahabatan terbuka dari koinonia yang sejati perlu didefinisikan secara lebih spesifik. Sebab hal itu bukan semata-mata persahabatan yang mencakup perbedaan dan ketegangan di antara orang-orang, melainkan persahabatan yang merangkul mereka yang menderita. Tidaklah cukup untuk mengatakan bahwa sama seperti Allah mengasihi "yang lain", demikian pula gereja harus mengasihi "yang lain". Bagi Moltmann, cinta sejati dan koinonia yang ditimbulkannya mengandaikan penderitaan Allah dan kita, baik sebagai kualitas esensial dari kepedulian kita yang rentan dan sebagai karakteristik pengalaman solidaritas hidup kita dengan penderitaan dunia. Mereka yang tidak mau membuka diri terhadap penderitaan tidak dapat mencintai. "Memang, hanya ketika gereja menerima penderitaan, ia dapat menulari orang-orang dengan harapan, karena dengan demikian kabar baik yang diberitakannya menjadi dapat dipercaya." (dalam Rhodes, 2000, hal. 44). Orang yang menderita terutama yang tertindas sangat merindukan penghiburan yang datang dari solidaritas orang lain kepada mereka. Moltmann berpendapat bahwa dalam Kitab Keluaran, Allah tidak hanya membebaskan orang dari 
penindasan, Allah tetap bersama mereka yang dibebaskan sebagai penghibur mereka dan sebagai dasar untuk perjuangan mereka yang berkelanjutan. Jadi, koininia mempertahankan solidaritas dengan mereka yang belum bebas dari penderitaan, baik di dalam maupun di luar komunitas iman. Keyakinan kuat Moltmann tentang panggilan gereja untuk menjadi koinonia persahabatan terbuka membawanya untuk menekankan kebebasan dan kesetaraan dalam komunitas dan keterbukaan dinamis kepada Roh Allah dalam cara gereja mengatur kehidupan dan ibadahnya. (dalam Rhodes, 2000).

Persekutuan persahabatan yang terbuka berarti membuka sekaligus memberi ruang bagi perbedaan (yang lain). Hal ini senada dengan apa yang juga dikatakan oleh Levinas bahwa tanggung jawab kepada yang lain dimulai dari sikap membuka diri. "Membuka diri terjadi karena ada perasaan tidak aman dengan diri sendiri. Aku terlalu asyik dengan duniaku sendiri dan tertutup terhadap realitas lain di luar diriku. Sikap membuka diri dapat membuat aku merasa bersalah terhadap yang lain". (dalam Baghi, 2012, hal. 69)

Perasaan bersalah tersebut muncul jika seseorang menutup mata ketika menyaksikan penderitaan orang lain. Seseorang tak dapat menyebut dirinya adil dan benar jika hanya berurusan dengan dirinya sendiri serta menutup diri terhadap kehadiran yang lain.

Lebih lanjut Levinas menyebut bahwa membuka diri berarti memberi. Memberi hanya mungkin dari sikap yang terbuka, dan orang 
yang terbuka biasanya lebih rela memberi. Hal terpenting dari sikap membuka diri dan memberi bukan terletak pada "apa" yang akan diberikan. Tidak ada pemberian yang lebih besar selain "memberi diri," dan pemberian diri ini adalah hidup. (dalam Baghi, 2012, hal. 70). Oleh karena itu, memberi diri berkenaan dengan memberi hidup untuk yang lain. Hal tersebut tepat sebagaimana yang Yesus katakan "Tidak ada kasih yang lebih besar daripada kasih seorang yang memberikan nyawanya untuk sahabat-sahabatnya" (Yoh. 15:13).

Konsep persahabatan terbuka pada hakikatnya merupakan model hospitalitas Kristiani ala Moltmann. Moltmann awalnya meminjam definisi tentang persahabatan dari teori moral Kantian. Dalam istilah Kant, persahabatan adalah hubungan pribadi yang menggabungkan antara "menghormati kebebasan orang lain dengan kasih sayang yang mendalam untuknya sebagai pribadi". (McDugall, 2005, 142-143). Kemudian Moltmann mengembangkan maknanya sedemikian rupa sehingga benar-benar sesuai dengan hubungan pribadi yang membentuk kehidupan persekutuan trinitarian. Persahabatan terbuka bergantung pada keinginan untuk berbagi diri sepenuhnya dalam kehidupan individu lain dan pada pengakuan atas perbedaan atau individualitas orang lain. Selain itu, persahabatan terbuka didasarkan pada timbal balik dan kesetaraan yang sempurna di antara manusia. Seseorang tidak mengambil atau memiliki yang lain, dan keduanya tidak saling tunduk. Sebaliknya, masingmasing menciptakan ruang bagi kebebasan orang lain. 
Persekutuan persahabatan terbuka pada akhirnya tak hanya berbicara tentang penderitaan, tetapi tentang cinta sejati yang keluar dari Allah kepada segenap ciptaan. Gereja ada untuk merayakan cinta yang sangat berlimpah. Dengan merangkul ketegangan dan perbedaan, konflik dan penderitaan, gereja yang hidup dalam persahabatan terbuka menuai manfaat dengan merasakan cinta dan sukacita. (Moltmann, 1979). Dalam konteks masa kini, menarik untuk mencermati ulasan Linna Gunawan bahwa gereja masa kini "harus berani terbuka menerima siapa saja yang datang. Setiap orang mendapat pelayanan yang setara tanpa dibedakan. Siapapun diterima masuk dalam komunitas gereja sekalipun mereka berbeda termasuk mereka yang cacat secara fisik dan mental, serta berbeda orientasi seksualnya". (Gunawan, 2019, hal. 73). Lebih lanjut, ia mengatakan bahwa penghargaan terhadap talenta, bakat atau karunia setiap anggota gereja menjadi salah satu ciri kasih yang menerima, dan hal ini perlu dikembangkan oleh gereja. (Gunawan, 2019)

\section{KESIMPULAN}

Kritik Moltmann terhadap konsep koinonia tentu bukanlah tanpa alasan. Konsep yang sudah dikenal luas tersebut ternyata mengandung potensi bahaya saat diterapkan dengan cara yang keliru dan dilandasi dengan keyakinan yang kurang tepat, seperti halnya yang terjadi dalam clerical monotheism yang justru tak mencerminkan kesetaraan dan cinta kasih melainkan mengedepankan relasi dominasi-subordinasi. Kritik 
tersebut menjadi cerminan bahwa berteologi tidak bersifat kaku dan tetap. Berteologi adalah sebuah proses yang tak kunjung usai sebagai usaha manusia memahami Allah dan sesama (sang liyan). Kritik Moltmann seharusnya mampu menjadi sumbangsih positif bagi gereja dalam menerapkan prinsip eklesiologi-nya, khususnya terkait konsep koinonia yang seharusnya menjangkau sang liyan yang asing, yang berbeda, yang kerap kali dianggap sebagai musuh. Gereja sebagai persekutuan persahabatan yang terbuka adalah komunitas yang mampu merangkul dan merayakan perbedaan dengan sang liyan sebagai sesama penyandang gambar dan rupa Sang Pencipta.

\section{DAFTAR PUSTAKA}

Adimihardja, K. (2011). Metode Penelitian Sosial : Suatu Teknik Penelitian Bidang Kesejahteraan Sosial Dan IImu Sosial Lainnya (J. Budhi (ed.)). PT Remaja Rosdakarya.

Adiprasetya, J. (2002). Berteologi dalam Perjumpaan dengan yang lain. Jurnal Teologi Proklamasi, 2(1), 45-54.

Adiprasetya, J. (2018). The Good yet Missing Innkeeper and the Possibility of Open Ecclesiology. In Ecclesiology. https://doi.org/10.1163/17455316-01402006

Baghi, F. (2012). Pengakuan, Hospitalitas, Persahabatan (Etika Politik dan Postmodernisme). Ledalero.

Derrida, J. (2005). The Politics of Friendship, terj. George Collins. Verso.

Gunawan, L. (2019). Spiritualitas Gereja Persahabatan: Memikirkan Ulang Konsep Bergereja dalam Konteks Dunia yang Serba Terhubung. Quaerens: Journal of Theology and Christian Education, 1(1), 67-78. https://doi.org/10.46362/quaerens.v1i1.17

Hegstad, H. (2013). The Real Church: An Ecclesiology of the Visible. Pickwick Publications. 
Karkkainen, V.-M. (2005). The Trinitarian Doctrines of Jurgen Moltmann and Wolfhart Pannenberg in the Context of Contemporary Discussion. In P. C. Phan (Ed.), The Cambridge Companion to the Trinity (hal. 223-242). Cambridge University Press.

Karkkainen, V.-M. (2017). Hope and Community: A Constructive Christian Theology for the Pluralistic World. Eerdmans publishing Company.

Knitter, P. F. (2008). Pengantar Teologi Agama-agama. Kanisius.

Kristeva, J. (1991). Strangers to Ourselves, terj. Leon S. Roudiez. Columbia University Press.

Lakawa, S. E. (2002). Perempuan Sebagai yang Lain: Keberanian Menggeser Paradigma Berteologi. Jurnal Teologi Proklamasi, 2(1), 13-44.

Levinas, E. (2000). Time and Other, terj. Ricard A. Cohen. Duquesne University Press.

McDugall, J. A. (2005). Pilgrimage of Love: Moltmann on the Trinity and Christian Life. Oxford University Press.

Moltmann, J. (1975). Theology of Hope. Harper \& Row.

Moltmann, J. (1979). Hope for the Church. Abingdon Press.

Moltmann, J. (1993). Trinity and the Kingdom: The Doctine of God. Fortress Press.

Rhodes, J. S. (2000). Jürgen Moltmann: The Comfort And Challenge of Open Friendship. The Asbury Theological Journal, 55(1), 41-49.

Sasongko, N. (2015). Toward a Nonviolent Koinonia. Ecclesiology. https://doi.org/10.1163/17455316-01103005

Slade, P. (2009). Open Friendship In A Closed Society: Mission Mississippi and A Theology of Friendship. Oxford University Press.

Tinambunan, D., \& Toruan, R. L. (2010). Orang Batak Kasar? Membangun Citra dan karakter. Elex Media Komputindo.

Volf, M. (1998). After Our Likeness: The Church as the Image of the Trinity. Eerdmans publishing Company. 